\title{
В поисках решения загадки структуры капитала: поведенческий подход
}

\author{
Солодухина А.В. ${ }^{81}$, Репин Д.В. ${ }^{82}$
}

Как известно, неоклассики провозгласили проблему структуры капитала загадкой. В конце конџов Майерс объявил загадку решенной. Однако при эмпирической проверке неоклассических (или традиционных) теорий стало ясно, что появились новые загадки. Эмпирические исследования показали, что компании почему-то не пользуются оптимальным соотношением долга к капиталу, хотя, по теории компромисса, оно должно максимизировать стоимость компании. Напротив, компании позволяют соотношению долг/капитал свободно дрейфовать, копируют его у других компаний в отрасли либо же поддерживают на необъяснимо низком уровне, но при этом входят в число наиболее успешных компаний в мире. Стало быть, компании пользуются какими-то другими соображениями при формировании структуры капитала, и притом довольно эффективными. Тогда возникают вопросы: какова же все-таки реальность? почему она именно такая? как ее смоделировать? Вот новые загадки, которые пытается решить поведенческая парадигма. Выход за рамки рачионального и эффективного мира, созданного традииионной теорией финансов, признание человека (и экономического агента) ограниченно рациональным и, следовательно, способным совершать ошибки, а также отказ от жесткого нормативного подхода, оказались довольно плодотворными. Представители поведенческой школы создали ряд интересных теорий, описывающих прочессс формирования структуры капитала в корпорачиях, среди которых - теория отслеживания рынка, теория информационных каскадов, теория автономии инвестиций менеджеров и теории влияния личности менеджера на структуру капитала. В статье рассматривается три этапа перехода от традиционной парадигмы $\kappa$ поведенческой: эмпирическая несостоятельность традиционных теорий структуры капитала, структура капитала глазами исследователей и поведенческие теории структуры капитала.

\section{$J E L: G 32$}

Ключевые слова: структура капитала, поведенческие финансы, теория отслеживания рынка, теория информационных каскадов, теория автономии инвестиций менеджеров

\footnotetext{
${ }^{81}$ Солодухина Анна Владимировна - аспирантка кафедры «Финансы и кредит» экономического факультета МГУ, автор и преподаватель курса «Поведенческие финансы» на кафедре «Финансы и кредит» экономического факультета МГУ, сотрудник Научно-исследовательской лаборатории корпоративных финансов при факультете экономики ГУ ВШЭ.

${ }^{82}$ Репин Дмитрий Владимирович - PhD, профессор ГУ ВШЭ. Руководитель Бизнес-инкубатора ГУ ВШЭ, один из ведущих специалистов в области поведенческих финансов в России.
} 


\section{Введение}

Corporate capital structure is a puzzle. Myers

Corporate capital structure is enigma. Kamath

Corporate capital structure is dilemma. Stiglitz

Corporate capital structure is a mystery.

The Economist

Как известно, неоклассики провозгласили проблему структуры капитала загадкой. Также известно, что загадок не отгадывает только ленивый. Структура капитала не стала исключением: много копий было сломано, много трудов написано, много теорий создано. Словом, о структуре капитала уже сказано столько, что, казалось бы, вряд ли стоит вновь поднимать эту тему. Однако с появлением нового направления в теории финансов поведенческих финансов - ситуация несколько изменилась: выход за рамки традиционной парадигмы, подкрепленный эмпирическими исследованиями, добавил много нового в проблему структуры капитала. Смену парадигм определили результаты эмпирической проверки традиционных теорий. Так, когда были протестированы основные теории структуры капитала, - теория компромисса и теория иерархии, стало ясно, что теория далека от реальности. Причем настолько далека, что даже апологеты неоклассической теории финансов Фама и Френч [Fama and French, 2004] заявили, что «...теория иерархии как модель структуры капитала умерла». Примерно о том же говорили и эмпирические проверки теории компромисса. Итак, если традиционные теории «умирают» одна за другой, компании пользуются какими-то другими соображениями при формировании структуры капитала, то возникают вопросы: какова же все-таки реальность? почему она именно такая? и как ее смоделировать?

Вот новые загадки, которые пытается решить поведенческая парадигма. Принципиальное отличие поведенческой парадигмы от традиционной заключается в применении описательного подхода. Этот подход, в отличие от предписательного, или нормативного, подхода, который характерен для неоклассической школы, дает более реалистичное представление об экономических процессах. Кроме того, бихейвиористы не закрывают глаза на ограниченность рациональности экономических агентов, что также позволяет выйти за рамки жестких нереалистичных моделей эффективного рынка и рационального принятия решений, довлеющих над традиционными теориями. Смена подхода и принятие за отправную точку более реалистичного экономического агента оказались достаточно плодотворными: представители поведенческой школы разработали ряд любопытных теорий структуры капитала, которые мы представим вниманию читателя в данной статье. Этим теориям, безусловно, еще предстоит пройти проверку временем, однако уже сейчас они представляют несомненный интерес - как научный, так и практический. В связи с этим, а также в связи с отсутствием в отечественной литературе какой бы то ни было информации об этих новых теоретических разработках проблема структуры капитала вновь становится актуальной.

Таким образом, мы решили посвятить данную статью решению загадок структуры капитала в рамках поведенческой парадигмы. Структура статьи отражает историческую смену парадигм: от традиционной к поведенческой, через обескураживающие данные эмпирических исследований. Так, в первом разделе мы обратимся к традиционным теориям, прочно вошедшим во все учебники и программы курсов по экономике и финансам, - теории компромисса и теории иерархии. Здесь мы кратко напомним суть теорий и приведем эмпирические свидетельства, противоречащие их сути. 
Во втором разделе мы продолжим изучение эмпирических данных, но уже с более общей целью: мы предлагаем вниманию читателя сводную таблицу эмпирических исследований, в которых не только тестируются теории структуры капитала, но также выявляются факторы структуры капитала в реальных компаниях и специфика принятия решений в этой области. Приведенный анализ интересен еще и тем, что он показывает, что не все исследования дают достоверную оценку реальности. Результаты исследований настолько разнообразны, что позволяют доказать и опровергнуть любую «удобную» гипотезу. В чем причина и чему верить, обсуждается во втором разделе статьи.

Третий, заключительный раздел посвящен теоретическим разработкам, предложенным в рамках поведенческой парадигмы, которые являются ответом на эмпирическую несостоятельность традиционных теорий структуры капитала.

\section{1. Традиционные теории структуры капитала}

В данном разделе будут рассмотрены две основные теории структуры капитала, выдвинутые представителями неоклассической школы: теория компромисса и теория иерархии. Данные теории получили наибольшую известность и позиционировались как «хорошие» теории. Как известно, теория хороша тогда, когда применима на практике. Насколько хороши эти теории в действительности, насколько они соответствуют реальной корпоративной практике и нуждаются ли они в замене, мы исследуем в текущем и следующем разделах. Обе теории хорошо известны нам по традиционным учебникам финансов, поэтому здесь мы лишь кратко сформулируем суть теорий и обратим внимание на важные моменты. Также мы отметим основные нарекания, которые вызывают данные теории у исследователей. Более детально эмпирическая состоятельность теорий будет проанализирована во втором разделе.

\section{1. Теория компромисса (Trade-off Theory)}

Теория. Теория компромисса утверждает, что компания в процессе принятия финансовых решений стремится к некому оптимальному значению структуры капитала. Такое оптимальное соотношение между долгом и собственным капиталом в структуре капитала достигается тогда, когда предельные издержки долга (агентские издержки и издержки банкротства) и выгоды долга (выгоды от налогового щита и устранение проблем нехватки свободных денежных средств) уравниваются. Таким образом, увеличение цены на акции компании (которое соответственно приводит к уменьшению финансового рычага) должно инициировать выпуск долга со стороны компании - так она сохранит прежнее значение «долг/капитал».

Реальность. Однако в реальности этого не происходит. СЕО действительно ориентируются на цены акций при принятии решений о выпуске ценных бумаг [Graham and Harvey, 2001], однако действуют они с точностью до наоборот: в период высоких цен компании не увеличивают долг и не выкупают акции, как должны были бы, согласно теории компромисса, а выпускают долевые ценные бумаги [Asquith and Mullins, 1986; Baker and Wurgler, 2002; Jung, Kim, and Stulz, 1996; Marsh, 1982; Mikkelson and Partch, 1986]. Кроме того, Вэлч [Welch, 2004] обнаружил, что компании не стремятся возвращаться к своим оптимальным значениям «долг/капитал», как предписывает это теория компромисса, - не выпускают собственный капитал в периоды падения цены акций и не размещают долг, когда цена поднимается. Вместо этого они позволяют своей структуре капитала и значению «долг/капитал» свободно дрейфовать вслед за динамикой котировок акций.

Более того, многие исследователи [Kester, 1986; Titman and Wessels, 1988; Rajan and Zingales, 1995; Fama and French, 2002] обнаружили отрицательную корреляцию финансового рычага и доходности, что противоречит ключевой идее теории компромисса о выгодах от налогового щита. 


\section{2. Теория иерархии (Pecking Order)}

Теория. Теория иерархии исходит из того, что менеджеры корпорации лучше осведомлены о положении дел внутри компании, о качестве инвестиционных проектов и т.д., и это может порождать издержки неблагоприятного отбора, которые перевешивают выгоды и издержки, рассматриваемые в теории компромисса (Trade-off theory). Кроме того, в основе теории иерархии лежит предпосылка о том, что издержки выпуска инструментов капитала (в частности, транзакционные издержки и издержки информационной асимметрии) высоки. Вследствие этого фирмы для финансирования своих проектов будут использовать сначала собственные ресурсы (нераспределенную прибыль), затем безрисковый долг, затем рисковый долг, и только в самых крайних случаях (например, в случае финансовых проблем компании) пойдут на выпуск акций.

Реальность. Фама и Френч [Fama and French, 2004] представили два убедительных доказательства, опровергающие теорию иерархии. Во-первых, фирмы слишком часто выпускают акции: по результатам их эмпирического исследования 86\% фирм за период с 1983-го по 2003 год выпустили собственный капитал в той или иной форме. Во-вторых, фирмы обычно выпускают собственный капитал отнюдь не под давлением обстоятельств. То же самое касается и выкупов акций - компания это делает вовсе не по причине отсутствия инвестиционных проектов, для которых необходимо внешнее финансирование. На практике, как выяснили Фама и Френч, подобные финансовые решения компаний идут вразрез с теорией иерархии, а именно в период с 1973-го по 2002 год против теории иерархии «погрешили» 50\% компаний из выборки. По результатам своего исследования Фама и Френч заключают, что «...теория иерархии как модель структуры капитала умерла».

\section{2. Эмпирические исследования}

Существует довольно большое количество эмпирических исследований, и все они довольно сильно разнятся по выводам относительно того, как, под воздействием каких факторов складывается структура капитала в компаниях. Одни исследования говорят в пользу теории компромисса, другие - в пользу теории иерархии, третьи предполагают синтез нескольких теорий, а четвертые свидетельствуют против традиционных теорий. В связи с этим необходимо рассматривать не только конечные результаты исследований, но и анализировать выборку, использованную в исследовании, и, что более важно - метод исследования. Так, наиболее популярный метод изучения эмпирических данных регрессионный анализ, - на наш взгляд, не является корректным применительно к исследованиям структуры капитала. Дело в том, что, как отмечали исследователи [Веattie, Goodacre and Thomson, 2006], политика компаний в области структуры капитала является довольно разнородной - она варьируется не только в зависимости от размера компании, ее местоположения, отраслевой принадлежности и т.д., но и от специфических условий, в которых находится компания, а также от ее руководства. Регрессионный анализ агрегированных данных усредняет все существуюеее разнообразие факторов и методов формирования структуры капитала и в итоге не отражает реальной картины. На это обстоятельство также указывали Фама и Френч [Fama and French, 2004], которые выяснили, что отклонения от теории иерархии, например, сглаживаются при агрегировании данных, тогда как на более детализированном уровне эти отклонения становятся очевидными. Именно поэтому выводы относительно структуры капитала реальных компаний так разнятся от исследования к исследованию. В связи с этим необходимо выделять из множества исследований те, в которых применяются корректные методы анализа и которые тем самым обеспечивают более достоверные результаты.

В данном разделе мы приводим краткий анализ самых последних и самых значимых эмпирических исследований структуры капитала. В предложенной таблице указаны авторы 
исследования, параметры выборки и метод исследования, полученные результаты, а также комментарии касательно важных моментов исследования - чтобы обратить внимание читателя на достоинства, недостатки и степень достоверности исследования.

Таблица 1. Обзор эмпирических исследований факторов структуры капитала за последние 4 года

\begin{tabular}{|c|c|c|c|}
\hline $\begin{array}{c}\text { Авторы } \\
\text { исследования } \\
\text { и год }\end{array}$ & $\begin{array}{c}\text { Характеристики выборки и } \\
\text { метод исследования }\end{array}$ & Выводы & Комментарии \\
\hline $\begin{array}{l}\text { Kayhan, } \\
\text { Titman (2007) }\end{array}$ & 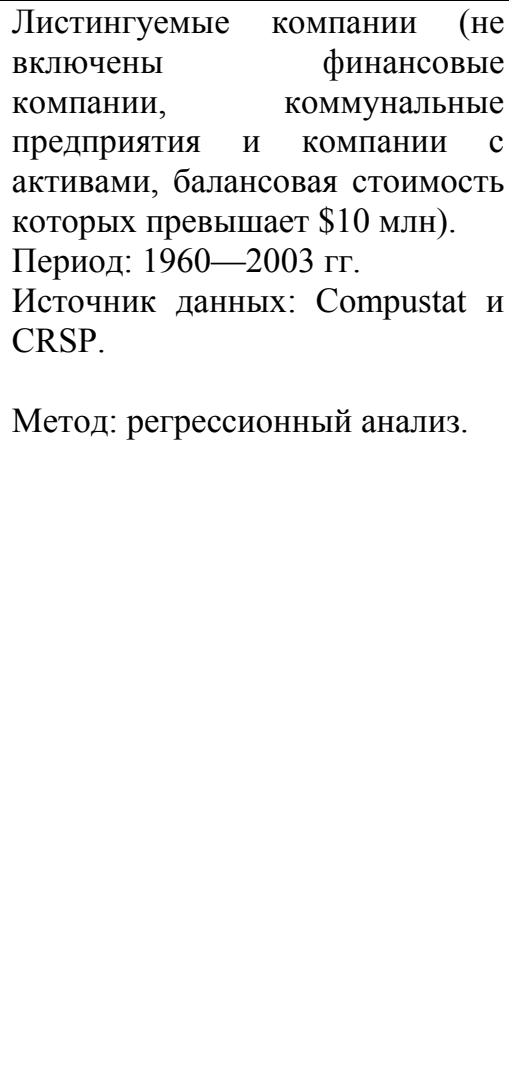 & 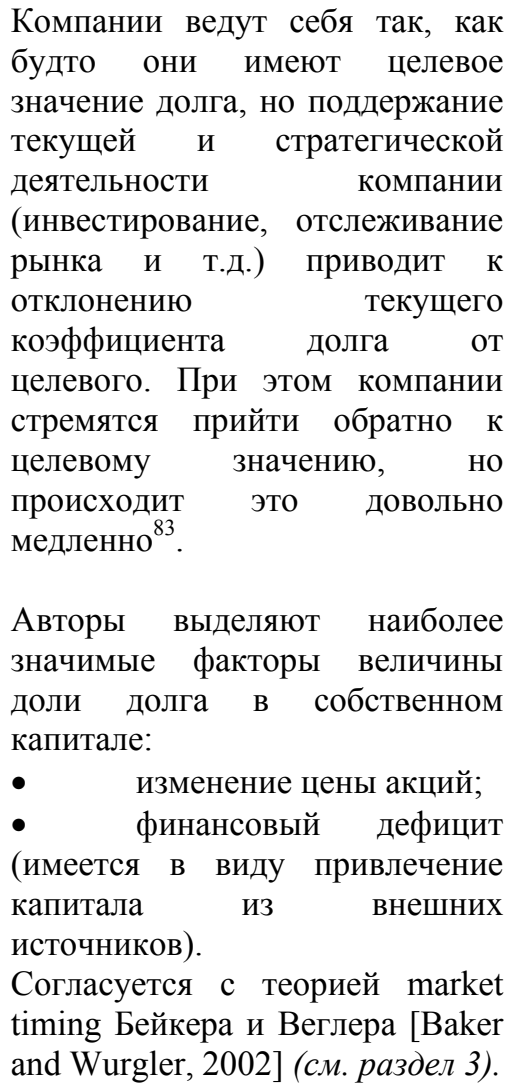 & \\
\hline $\begin{array}{l}\text { Beattie, } \\
\text { Goodacre, } \\
\text { Thomson } \\
(2006)\end{array}$ & $\begin{array}{l}\text { Листингуемые компании } \\
\text { Великобритании. } \\
\text { Метод: анкетирование. } \\
\text { Респонденты: финансовые } \\
\text { директора. } \\
\text { Кол-во заполненных анкет: } 192 \\
\text { (из } 560 \text { разосланных). } \\
\text { Дата проведения анкетирования: } \\
\text { июль } 2000 \text { г. }\end{array}$ & 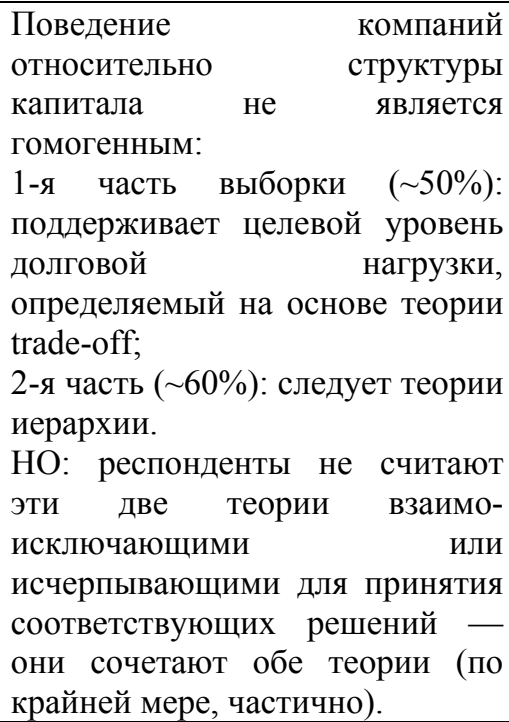 & $\begin{array}{lr}\text { Авторы обращают } \\
\text { внимание на то, что } \\
\text { политика компаний и } \\
\text { их поведение в } \\
\text { области структуры } \\
\text { капитала не являются } \\
\text { гомогенными, они } \\
\text { очень разнятся от } \\
\text { компании к } \\
\text { компании. В связи с } \\
\text { этим применение } \\
\text { регрессии как метода } \\
\text { исследования не } \\
\text { является корректным, } \\
\text { поскольку r этого } \\
\text { усреднение } \\
\text { многообразия исказит } \\
\text { картину до }\end{array}$ \\
\hline
\end{tabular}

\footnotetext{
${ }^{83}$ Касательно данного аспекта приведем исследование Фланнери и Рангана [Flannery and Rangan, 2005], целью которого является установление скорости возвращения доли долга к целевому значению. Авторы делают вывод, что в среднем компании действительно определяют для себя долгосрочную целевую структуру капитала и постепенно - по 1/3 в год - устраняют отклонение текущего значения от целевого.
} 


\begin{tabular}{|c|c|c|c|}
\hline & & $\begin{array}{l}\text { Авторы указывают на связь } \\
\text { размера компании и выбираемой } \\
\text { теории (политики) при } \\
\text { формировании структуры } \\
\text { капитала: крупные компании } \\
\text { более склонны поддерживать } \\
\text { некое целевое значение и не } \\
\text { склонны следовать финансовой } \\
\text { иерархии. } \\
\text { Респонденты также поддержали } \\
\text { значимость таких факторов } \\
\text { структуры капитала, как: } \\
\text { • } \\
\text { • налоговый щит; } \\
\text { затруднения (finanсіal distress); } \\
\text { • агентские издержки; } \\
\text { • } \\
\text { асимметрия. }\end{array}$ & \begin{tabular}{l}
\multicolumn{2}{l}{ неузнаваемости. } \\
Аналогичная идея \\
была высказана \\
Фамой и Френчем \\
[Fата and French, \\
$2004]$ относительно \\
исследования \\
агрегированных и \\
дезагрегированных \\
данных (см. ниже).
\end{tabular} \\
\hline $\begin{array}{ll}\text { Fama, French } \\
(2004)\end{array}$ & $\begin{array}{l}\text { Компании, торгуемые на NYSE, } \\
\text { АMЕХ, и Nasdaq. В выборку не } \\
\text { включались финансовые } \\
\text { коммунальные компании. } \\
\text { Объем выборки: от } 2951 \text { за } \\
\text { период 1973-1982 гг. (из них } \\
617 \text { крупных компаний) до } 4417 \\
\text { за период 1993-2002 гг. (из них } \\
712 \text { крупных). } \\
\text { Период: 1973-2002 гг. } \\
\text { Источник данных: CRSP и } \\
\text { Соmpustat. }\end{array}$ & $\begin{array}{lrr}\text { Авторы } & \text { находят } & \text { свидетельства } \\
\text { против } & \text { теории } & \text { иерархии: } \\
\text { слишком } & \text { частые } & \text { выпуски } \\
\text { капитала } & (54-72 \% & \text { компаний } \\
\text { выборки } & \text { эмитировали } & \text { капитал } \\
\text { каждый год) и выкупы капитала } \\
(20 \% & \text { компаний } & \text { выборки } \\
\text { производили выкупы } & \text { каждый } \\
\text { год). } & & \end{array}$ & 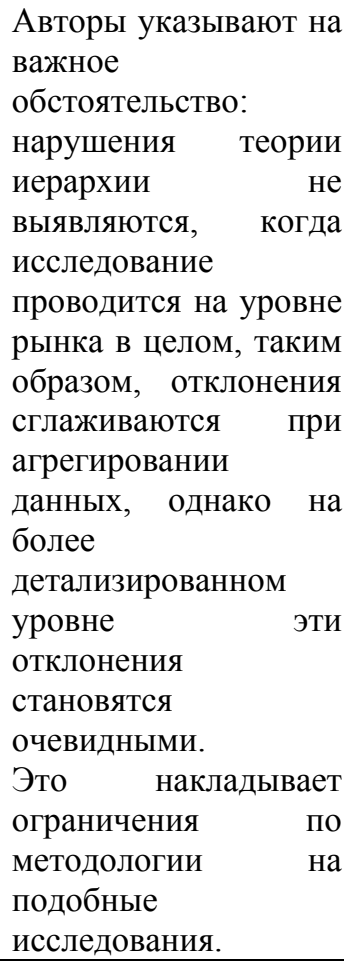 \\
\hline
\end{tabular}




\begin{tabular}{|c|c|c|c|}
\hline $\begin{array}{l}\text { Frank } \quad \text { and } \\
\text { Goyal }\end{array}$ & 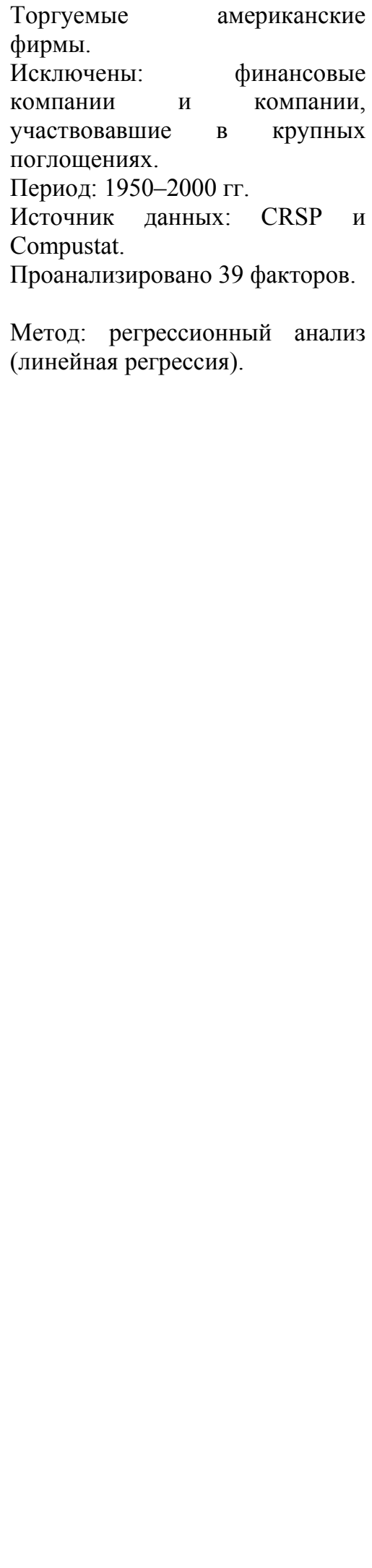 & 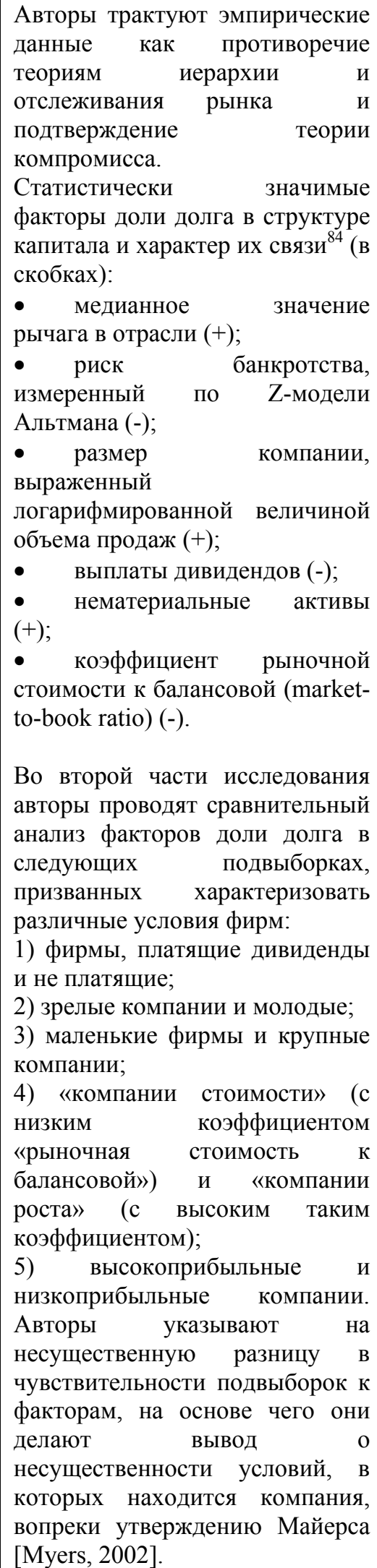 & 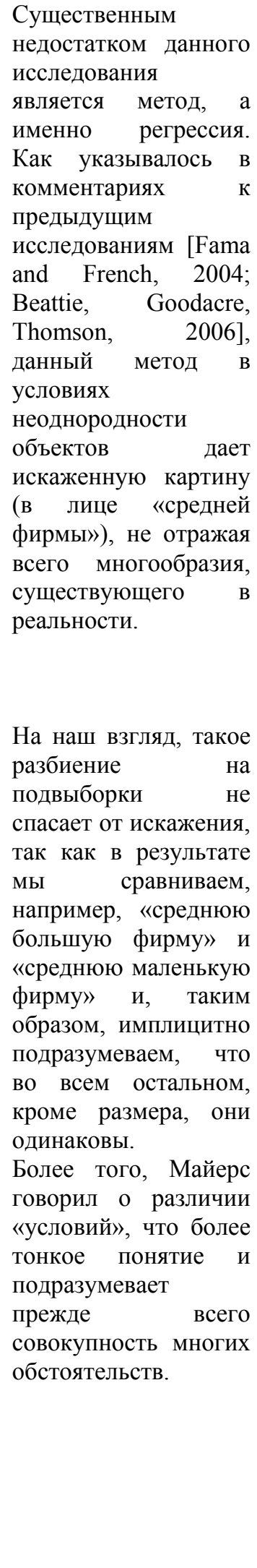 \\
\hline $\begin{array}{l}\text { Bevan } \\
\text { Danbolt } \\
(2002) .\end{array}$ & $\begin{array}{l}822 \text { компании } \text { Великобритании } \\
\text { (финансовые компании не } \\
\text { включались). } \\
\text { Источник данных: Datastream. } \\
\text { Период: 1991-1997 гг. }\end{array}$ & $\begin{array}{lll}\text { Автор } & \text { выявляет ряд } \\
\text { факторов долимых долга: } \\
\text { - } & \text { размер }(+) ; \\
\bullet & \text { волатильность доходов } \\
(+) ; & \end{array}$ & $\begin{array}{l}\text { Сомнительность } \\
\text { результатов, } \\
\text { полученных таким } \\
\text { методом, у уже } \\
\text { комментировалась } \\
\end{array}$ \\
\hline
\end{tabular}

\footnotetext{
${ }^{84}$ Где «+» означает положительную корреляцию фактора и долговой нагрузки, а «-» - отрицательную
} корреляцию. 


\begin{tabular}{|c|c|c|c|}
\hline & Метод: регрессионный анализ. & 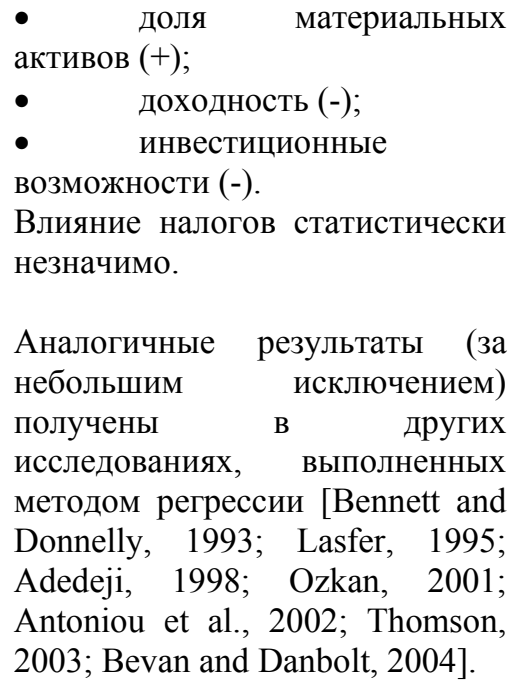 & выше. \\
\hline
\end{tabular}

Как мы видим из таблицы, основная масса исследований использует метод регрессионного анализа, недостатки которого были неоднократно упомянуты ранее. Более корректным, на наш взгляд, является метод анкетирования, поскольку он позволяет анализировать данные на уровне фирмы и учитывать различные условия и параметры деятельности компании. В числе таких исследований опрос, проведенный Бити, Гудакром и Томсоном [Beattie, Goodacre and Thomson, 2006], который был представлен в таблице 1, а также опрос, выполненный Грэмом и Харви [Graham and Harvey, 2001]. В ходе опроса авторы получили много интересных результатов, которые хотелось изложить более детально, чем позволяет формат таблицы, а потому мы вынесли рассмотрение данного исследования за рамки таблицы.

Опрос Грэма и Харви [Graham and Harvey, 2001]. В опросе авторы тестировали основные теории структуры капитала: традиционные теории - теорию компромисса (the Trade-off Theory) и теорию иерархии (Pecking Order), а также поведенческую теорию отслеживания рынка (Market Timing Theory) Бейкера и Веглера [Baker and Wurgler, 2002]. Респондентами данного опроса выступали СЕО американских и канадских компаний, варьирующихся по размеру и отраслевой принадлежности. Результаты исследования показывают, какие факторы на самом деле определяют политику структуры капитала и насколько практика согласуется с существующими теориями.

1) Теория компромисса (the Trade-off Theory).

Согласно теории, основными факторами, которые должны учитываться при формировании структуры капитала, являются выгоды от налогового щита и издержки банкротства, однако СЕО в рейтинге значимости факторов при формировании структуры капитала ставят их на 6-е и 10-е места соответственно. Фактор выгод от налогового щита более значим для больших, регулируемых компаний, которые платят дивиденды (учитывая высокие ставки корпоративного налога в подобных компаниях, стремление менеджмента использовать долг естественно). Также характерно, что строгого целевого соотношения долга и собственного капитала придерживаются только 10\% опрошенных СЕО, остальные $90 \%$ констатируют либо отсутствие такого ориентира (19\%), либо наличие «гибкого» ориентира (37\%), либо наличие «более или менее жесткого» ориентира (34\%). Целевое значение оказывается важным для молодых СЕО или СЕО с небольшим стажем работы на данной должности; чем опытнее СЕО, тем меньше он ориентируется на целевое значение и больше полагается на свой опыт.

2) Другие теории.

Исследователи задали вопрос: «задумывалась ли серьезно Ваша компания о возможности выпустить обыкновенные акции? Если да, то под влиянием каких факторов?». Респондентам было предложено 13 вариантов ответа. Вторым и третьим по значимости факторами были отмечены «величина, на которую переоценены или недооценены на рынке 
акции компании» $(66,94 \%)$ и «недавнее увеличение цены акций, так как в таком случае новый выпуск акций можно продать по более высокой цене» (62,60\%), то есть факторы, которые поддерживают теорию отслеживания рынка (Market Timing Theory) Бейкера и Веглера [Baker and Wurgler, 2002]. Пятым по важности фактором было отмечено поддержание целевого значения долговой нагрузки по отношению к капиталу $(51,59 \%)$, однако, как мы видели выше, данное соотношение вряд ли согласуется с теорией компромисса. На девятом месте - стремление использовать такой же объем собственного капитала, что и другие компании в отрасли (22,95\%): здесь мы наблюдаем имитирующее поведение менеджеров, пытающихся копировать решения менеджеров других компаний. Десятое место занимает фактор имиджевого характера, поскольку посылом к выпуску акций в данном варианте является соображение менеджеров о том, что «выпуск акций производит на инвесторов лучшее впечатление, чем выпуск долга» $(21,49 \%)$. И наконец, одиннадцатым в списке значимости является фактор недоступности других источников финансирования, таких как долг, конвертируемые облигации и т.д. $(15,57 \%)$ - подчеркнем, что именно это соображение, согласно теории иерархии, должно руководить менеджерами при принятии финансовых решений.

Таким образом, исследователи приходят к выводу, что ни теория иерархии, ни теория компромисса не применяются на практике в чистом виде, от начала и до конца, финансовые директора руководствуются ими лишь отчасти, совмещают их и дополняют практикой отслеживания рынка. В результате получается смесь принципов, основанных на теоретическом фундаменте, опыте и интуиции.

\section{3. Поведенческие теории структуры капитала}

\section{1. Теория отслеживания рынка (Market Timing Theory)}

В корпоративных финансах термин «отслеживание рынка» (market timing) обозначает практику корпораций эмитировать долевые ценные бумаги в период высоких цен на рынке и выкупать акции в период низких цен. Таким образом, менеджеры извлекают выгоду из временных отклонений стоимости собственного капитала относительно стоимости других форм капитала. Согласно опросам и эмпирическим исследованиям [Graham and Harvey, 2001], данная практика широко распространена среди управляющих западными корпорациями и имеет следующие особенности:

1) корпорации стремятся эмитировать долевые бумаги (вместо долговых), когда рыночная стоимость компании становится высокой по отношению к балансовой стоимости и рыночной стоимости компании в прошлых периодах, и выкупать долевые бумаги, когда рыночная стоимость относительно низка ${ }^{85}$;

2) корпорации стремятся эмитировать долевые бумаги, когда инвесторы настроены чересчур оптимистично по поводу будущих прибылей компании ${ }^{86}$;

3) анализ долгосрочных доходностей акций, наблюдаемых после проведения таких операций, показывает, что практика отслеживания рынка благоприятно влияет на последующую доходность акций компании.

Бейкер и Веглер, авторы теории, обнаружили в своем исследовании [Baker and Wurgler, 2002] еще одно обстоятельство: данная практика имеет сильное долгосрочное влияние на

\footnotetext{
85 См. работы Марша, Аскита и Маллинса, Коражчык, Лукаса и МакДональда, Юнга, Кима и Штульца, Ховакимяна, Оплера и Титмана [Marsh, 1982; Asquith and Mullins, 1986; Korajczyk, Lucas, and McDonald, 1991; Jung, Kim, Stulz, 1996; Hovakimian, Opler, and Titman, 2001]; выход на IPO совпадает с высокой рыночной стоимостью в работах Луграна, Риттера и Рыдквиста, а также Пагано, Панетта и Зингалеса [Loughran, Ritter, and Rydqvist, 1994; Pagano, Panetta, and Zingales, 1998]; выкуп капитала осуществляется при низкой рыночной стоимости в статье Икенберри, Лаконишока и Вермелена [Ikenberry, Lakonishok, and Vermaelen, 1995].

${ }^{86}$ См. работы Луграна и Риттера, Раджана и Сервеса, Тео, Вэлча и Вонга, а также Дэниса и Capина [Loughran and Ritter, 1997; Rajan and Servaes, 1997; Teoh, Welch and Wong, 1998; Denis and Sarin, 2001].
}

Выпуск \#1(5), 2008 С Электронный журнал Корпоративные Финансы, 2008 
формирование структуры капитала. Дело в том, что, согласно традиционным теориям структуры капитала, корпорации, после того как они воспользовались благоприятной ситуацией на рынке капитала и в результате изменили структуру капитала, должны перебалансировать полученную структуру капитала так, чтобы вернуться к оптимальному соотношению собственного капитала и долга, и тогда операции по отслеживанию рынка никак не отразятся на структуре капитала. Однако в реальности наблюдается существенное влияние прошлой истории рынка (и благоприятных возможностей по выпуску или выкупу акций, представившихся менеджменту компании в прошлом) на структуру капитала, причем глубина такого воздействия составляет 10 и более лет. То есть структура капитала компании по состоянию на 2000 год сильно зависит от колебания соотношения рыночной и балансовой стоимости, которое имело место в 1990 году и ранее. Именно такая долгосрочность эффекта не поддается объяснению в рамках традиционных теорий структуры капитала. Так, в теории компромисса (the Trade-off Theory) соотношение рыночной стоимости к балансовой и его временные колебания (а именно такие колебания и используются менеджментом при отслеживании рынка) имеют исключительно краткосрочный эффект. В теории иерархии менеджеры вообще стараются всеми силами избежать эмиссии собственного капитала. В свою очередь Бейкер и Веглер на основе собственного исследования и других эмпирических данных предложили следующую теорию структуры капитала: «структура капитала формируется в результате попыток менеджмента отслеживать рынок капитала и представляет собой суммарный итог всех таких попыток» ${ }^{87}$. Таким образом, в данной теории не существует оптимальной структуры капитала - структура капитала складывается не в результате стратегического планирования, а в результате реализации сиюминутных благоприятных возможностей, представляющихся на рынке капитала в тот или иной момент.

Также хотелось бы отметить еще одну интересную работу в рамках концепции отслеживания рынка - статью Джентера [Jenter, 2005]. Результаты его исследования показывают, что топ-менеджеры систематически не разделяют взгляды рынка на стоимость акций своих компании. Им постоянно кажется, что рынок неправильно оценивает акции, при этом характерно, что менеджеры фирм с низкой капитализацией склонны считать, что акции компании недооцениваются рынком, а менеджеры компаний с высокой капитализацией, наоборот, полагают, что акции их компании переоцениваются. Подчеркнем, что здесь акцентом является субъективное восприятие менеджеров того, как рынок оценивает акции, и это восприятие является важным фактором решений и поведения менеджеров при проведении IPO, дополнительной эмиссии акций, выкупа, а также слияний и поглощений. Таким образом, даже если предположить, что рынок капитала абсолютно рационален и цены акций отражают фундаментальную стоимость компании, то аллокативная функция рынка нарушается, так как менеджеры воспринимают ценовые сигналы, поступающие с рынка, как иррациональные и исходя из этого принимают решения в области финансовой и инвестиционной политики. В результате IPO и изменения в структуре капитала могут быть вызваны всего лишь благоприятными возможностями, появившимися на рынке капитала, а не реальной потребностью компании в ресурсах. Слияния и поглощения могут быть предприняты менеджментом не потому, что сделка добавляет стоимость, а потому, что переоцененный капитал можно использовать как денежный ресурс. ${ }^{88} \mathrm{~B}$ свою очередь проекты с отрицательной приведенной стоимостью могут быть приняты, если капитал в восприятии менеджеров является «дешевым», а проекты с положительной приведенной стоимостью могут быть отклонены, если капитал, по мнению менеджеров, является «дорогим».

\footnotetext{
${ }^{87}$ «...capital structure is the cumulative outcome of attempts to time the equity market» [Baker and Wurgler, 2002, p.3].

${ }^{88}$ См. также работу Шляйфера и Вишны [Shleifer and Vishny, 2003], в которой представлена модель, где сделки слияний и поглощений осуществляются не по стратегическим соображениям, а в результате неправильной оценки капитала рынком, чем тут же спешат воспользоваться менеджеры.
}

Выпуск \#1(5), 2008 С Электронный журнал Корпоративные Финансы, 2008 


\section{2. Теория информационных каскадов (Informational Cascades Theory)}

В основе теории информационных каскадов, предложенной Бихчандани, Хиршляйфером и Вэлчем [Bikhchandani, Hirshleifer and Welch, 1992; Idem., 1998), лежит стадное поведение (herding) экономических агентов. Основная идея теории заключается в том, что во многих ситуациях «оптимальной стратегией поведения индивида является повторение действий (или решений) его предшественников, оказавшихся в аналогичной ситуации, вне зависимости от личной информации, которой он располагает». В этих случаях возникает то, что авторы называют информационным каскадом (informational cascade). Приложение данной теории очень широко - это и бизнес, и политика, и криминалистика, и повседневная деятельность человека, поскольку человек постоянно, во всех сферах своей деятельности, сталкивается с проблемой принятия решений. Применительно к структуре капитала информационный каскад может проявляться в имитационном поведении менеджеров: они часто слепо следуют популярным в текущий момент методам управления это касается финансовых и инвестиционных решений и т.д., не исключая структуры капитала. Менеджеры обращают внимание на поведение других менеджеров - как в своей компании, так и в других, - и копируют его в похожих ситуациях при решении аналогичных задач. Тем более что определение оптимальной структуры капитала или оптимальной финансовой политики требует от менеджеров времени и высокой компетентности, которыми они могут и не располагать. В отношении структуры капитала теория информационных каскадов может работать в следующих направлениях:

- Менеджеры могут копировать структуру капитала компании-лидера отрасли (заметим, что Фрэнк и Гойал [Frank and Goyal, 2003] на основе результатов своего эмпирического исследования отмечают, что медианное значение долговой нагрузки в отрасли является одним из важнейших факторов, определяющих структуру капитала компании. Мы приводим этот факт не как доказательство данной теории, но лишь как ее подкрепление).

- Менеджеры могут вслед за большинством пользоваться наиболее популярными методами формирования структуры капитала - в соответствии с теорией стационарного соотношения, или теорией иерархии, или, следуя примеру своих коллег в других компаниях, практиковать принцип отслеживания рынка, или сочетать несколько популярных методов и теорий.

\section{3. Теория автономии инвестиций менеджеров (Managerial Investment Autonomy Theory)}

Диттмар и Такор [Dittmar and Thakor, 2007] развивают концепцию отслеживания рынка, предложенную Бейкером и Веглером [Baker and Wurgler, 2002]. Они полагают, что менеджер принимает во внимание как краткосрочную стоимость акций, складывающуюся на рынке сразу после осуществления инвестиций, так и долгосрочную стоимость капитала компании. Краткосрочная реакция цены на реализацию компанией инвестиционного проекта зависит от того, как инвесторы оценивают этот проект. Менеджеры пытаются определить, каково будет восприятие проекта на рынке капитала и насколько оно будет совпадать с их представлением, и на основе этого формируют ожидания относительно реакции цены на принятие инвестиционного проекта. Именно это ожидание, по мнению авторов теории, определяет решение об эмиссии. Таким образом, центральным моментом при принятии финансовых решений является степень согласия инвесторов с принимаемыми менеджерами решениями, то есть то, насколько инвесторы разделяют оценки менеджеров относительно успешности, правильности, доходности проекта. Согласно предложенной модели, компания будет выпускать инструменты капитала, когда рыночная стоимость ее акций и степень согласия менеджеров и инвесторов высоки, и будет выпускать долг, когда рыночная стоимость акций и степень согласия, напротив, низки. Авторы подчеркивают

\section{Выпуск \#1(5), 2008 이의 Электонный журнал Корпоративные Финансы, 2008}


принципиальное отличие от концепции отслеживания рынка Бейкера и Веглера: в их модели связь между эмиссией капитала и ценой акций возникает потому, что высокая стоимость акций свидетельствует о согласии инвесторов с действиями менеджеров на данный момент, тогда как в концепции отслеживания рынка эта связь возникает из-за переоцененности компании. То есть компании выпускают собственный капитал, когда цена на акции компании высока потому, что высокие цены на рынке свидетельствуют о том, что инвесторы в данный момент склонны позитивно оценивать решения менеджеров. Таким образом, менеджеры будут использовать инструменты капитала для финансирования какого-либо проекта компании только в том случае, если им кажется, что инвесторы оценивают перспективы проекта так же, как и сами менеджеры. Если же у менеджеров нет уверенности, что их ожидания по проекту совпадают с ожиданиями инвесторов, они предпочитают выпустить долг. Диттмар и Такор протестировали свою теорию и получили ее эмпирическое подкрепление.

\section{4. Влияние личных качеств менеджеров на структуру капитала компании}

Еще несколько десятков лет назад Канеман, Тверски [Kahneman and Tversky, 1974, Idem.,1979, Idem.,1981, Idem., 1992] и другие исследователи в области психологии показали, что людям свойственны такие особенности, или отклонения, как чрезмерная самоуверенность и оптимизм (overconfidence and optimism), неприятие потерь (loss aversion), контекстное мышление (framing), прогнозирование с нарушением правила Байеса (nonBayesian forecasting) и многие другие. Как известно, менеджеры, определяющие структуру капитала, тоже люди и они тоже подвержены этим отклонениям. Так получили развитие исследования, изучающие влияние качеств менеджеров на принятие финансовых решений [Fairchild, 2005; Malmendier and Tate, 2002; Landier and Thesmar, 2004; Heaton, 2002; Gervais, Heaton and Odean, 2003]. В данном разделе мы рассмотрим основные работы, посвященные взаимосвязи менеджерских качеств и структуры капитала.

Хэкбарт [Hackbarth, 2004] на основе простой модели фирмы рассматривает, какое влияние оказывают оптимизм и самоуверенность менеджеров на принятие решений в области структуры капитала, а также на стоимость фирмы. В частности, автор показывает, что оптимистически настроенные и (или) чрезмерно уверенные менеджеры:

1) выбирают более высокие уровни долговой нагрузки,

2) эмитируют новые долговые обязательства более часто,

3) не следуют теории иерархии и

4) склонны отслеживать возможности на рынке (market timing), в результате чего формируется структура капитала.

Также автор указывает, что умеренно оптимистичные и уверенные менеджеры способствуют повышению стоимости компании, так как высокая долговая нагрузка сдерживает их возможные недобросовестные (по отношению к акционерам компании) действия по уводу внутренних ресурсов на сомнительные проекты (например, увеличение представительских расходов, финансирование проектов, не создающих стоимость, и т.д.).

Баррос и Александр [Barros and Alexandre, 2007] в своем исследовании тестируют гипотезу, сформулированную в исследовании Хэкбарта [Hackbarth, 2004] и ряде других, о том, что фирмы, управляемые оптимистичными и/или чересчур уверенными в себе менеджерами, обладают при прочих равных более левереджированной структурой капитала. В целях тестирования авторы предлагают различные метрики для выражения оптимизма и самоуверенности менеджеров. Основная часть этих метрик базируется на статусе менеджера - является ли он предпринимателем (например, основателем фирмы) или нет (нанятый 
менеджер) $)^{89}$; другая часть базируется на принципе владения менеджерами акциями своей компании. Эмпирический анализ данных ${ }^{90}$ демонстрирует сильную статистически значимую связь между предложенными метриками самоуверенности и оптимизма менеджеров и соотношением «долг/капитал» (положительная корреляция), что позволяет авторам говорить о самоуверенности и оптимизме менеджеров как об очень значимом факторе структуры капитала. Наряду с поведенческими факторами в исследовании также рассматриваются традиционные факторы структуры капитала. Так, в числе значимых факторов авторы указывают доходность, размер компании, дивидендные выплаты и долю материальных активов (tangibility), а также некоторые индикаторы качества корпоративного управления (corporate governance). По результатам исследования авторы заключают, что использование поведенческого подхода в исследованиях позволяет существенно продвинуться в понимании того, как принимаются решения в компаниях.

\section{Заключение}

В данной статье была рассмотрена структура капитала в контексте перехода от неоклассической, традиционной парадигмы к поведенческой. Как мы видели, традиционные теории структуры капитала оказались эмпирически несостоятельными, что приводит нас к двум выводам: во-первых, эти теории плохо описывают реальную корпоративную практику в этой области; и во-вторых, несмотря на свою известность, эти теории мало применяются на практике. Эмпирические исследования показывают, что компании почему-то не пользуются оптимальным соотношением долга к капиталу, хотя, согласно теории компромисса, оно должно максимизировать стоимость компании. Напротив, компании позволяют соотношению долг/капитал свободно дрейфовать, копируют его у других компаний в отрасли либо же поддерживают на необъяснимо низком (с точки зрения теории компромисса) уровне - возле нуля. Кроме этого, компании довольно охотно идут на выпуск акций, что противоречит теории иерархии, и при том часто это делают не от безысходности (то есть недоступности других источников финансирования), а с целью «сыграть» на текущей переоцененности капитала компании на рынке.

Используя эти и другие эмпирические данные, представители поведенческой школы попытались описать то, как в реальности происходит принятие решений, определяющих структуру капитала. В результате был создан ряд поведенческих теорий, выявивших интересные модели корпоративного поведения в вопросах структуры капитала. В частности, теория отслеживания рынка (Market timing theory) выявила, что для компаний не существует оптимального соотношения долг/капитал, они позволяют этому соотношению меняться. Такой свободный дрейф соотношения долга и капитала связан со стремлением компаний воспользоваться возникшей на рынке неправильной оценкой стоимости капитала компании. Отслеживание рынка и извлечение выгоды из текущей недооцененности или переоцененности капитала и определяет структуру капитала, и в этом смысле это и есть оптимальная стратегия. Теория информационных каскадов говорит нам о том, что структура капитала может выбираться не исходя из расчетов оптимальной структуры или складываться в зависимости от доступных в разные периоды жизни компании источников финансирования, а копироваться у других компаний или успешных, авторитетных менеджеров - для экономии времени и сил и во избежание ошибок. Теория автономии инвестиций менеджеров устанавливает связь между решениями менеджеров и ожидаемым восприятием инвесторами этих решений. Менеджеры реализуют только те решения, которые по их расчетам положительно воспримутся инвесторами и, соответственно, положительно скажутся на рыночной стоимости компании. Таким образом, структура капитала

\footnotetext{
${ }^{89}$ В основе такой метрики лежат эмпирические данные, свидетельствующие о том, что предпринимателям свойственно проявлять такие когнитивные отклонения более часто, чем нанятым работникам.

90 Авторы анализируют выборку бразильских компаний, торгуемых на бирже Сан Паоло (Воvеspa; за период 1998-2003 гг.), и используют метод панельной регрессии.
}

Выпуск \#1(5), 2008 С Электронный журнал Корпоративные Финансы, 2008 
складывается больше под влиянием инвесторов, проводниками желаний которых выступают менеджеры. Последняя группа теорий рассматривает влияние личных качеств менеджеров на формирование структуры капитала. Эти теории показывают, что личные качества менеджеров, особенно оптимизм и чрезмерная самоуверенность, являются существенным фактором структуры капитала, который не принимался во внимание ни одной традиционной теорией.

В завершение хочется отметить перспективность поведенческой парадигмы в разгадывании многих загадок теории финансов, появившихся в последние десятилетия как результат проведения многочисленных эмпирических тестов. Выход за рамки стереотипов, признание человека (и экономического агента) ограниченно рациональным и, следовательно, способным совершать ошибки, а также отказ от жесткого нормативного подхода уже принес первые плоды. И хотя пока нет стройной всеобъемлющей теории, что всегда отличало неоклассическую теорию финансов, самое важное, на наш взгляд, уже есть - понимание несовершенства и многовариантности реальности и принятие ее таковой.

\section{Литература}

1. Adedeji A. Does the pecking order hypothesis explain the dividend payout ratio of firms in the UK? // Journal of Business Finance \& Accounting, Vol. 25, Nos. 9/10, 1998, pp. 1127-1255.

2. Antoniou A., Guney Y., Paudyal K. Determinants of corporate capital structure: Evidence from european countries // Working Paper (Centre for Empirical Research in Finance, University of Durham, Durham), 2002.

3. Asquith P., Mullins D. Equity issues and offering dilution // Journal of Financial Economics № 15, 1986, pp. 61-89.

4. Baker M., Wurgler J. Market timing and capital structure // Journal of Finance № 57, 2002, pp. 1-32.

5. Barros L., Alexandre M. Overconfidence, managerial optimism and the determinants of capital structure // Working paper, 2007.

6. Beattie V., Goodacre A., Thomson S. Corporate financing decisions: UK survey evidence // Journal of Business Finance \& Accounting, № 33 (9-10), 2006, pp. 1402-1434.

7. Bennett M., Donnelly R. The Determinants of capital structure: Some UK evidence //British Accounting Review, Vol. 25, № 1, 1993, pp. 43-59.

8. Bevan A., Danbolt J. Capital structure and its determinants in the UK - a decompositional analysis // Applied Financial Economics, Vol. 12, № 3, 2002, pp. 159-70.

9. Bevan A., Danbolt J. Testing for inconsistencies in the estimation of UK capital structure determinants // Applied Financial Economics, Vol. 14, № 1, 2004, pp. 55-66.

10. Bikhchandani S., Hirshleifer D., Welch I. A Theory of fads, fashion, custom and cultural change as informational cascades // Journal of Political Economy, 100, 1992, pp. 992-1026.

11. Bikhchandani S., Hirshleifer D., Welch I. Learning from the behavior of others: Conformity, fads, and informational cascades // The Journal of Economic Perspectives, Vol. 12, № 3, 1998, 151-170.

12. Denis D., Sarin A. Is the market surprised by poor earnings realizations following seasoned equity offerings? // Journal of Financial and Quantitative Analysis, 36, 2001, pp. 169193.

13. Dittmar A., Thakor A. Why do firms issue equity? // Journal of Finance, 2007, forthcoming.

14. Fairchild R. The effect of managerial overconfidence, asymmetric information, and moral hazard on capital structure decisions // Working Paper, 2005.

15. Fama E., French K. Testing tradeoff and pecking order predictions about dividends and debt // Review of Financial Studies, 15, 2002, pp. 1-33.

16. Fama E., French K. Financing decisions: Who issues stock? // Working Paper, 2004. 
17. Flannery M., Rangan K. Partial adjustment toward target capital structures // Journal of Financial Economics, forthcoming, 2005.

18. Frank M., Goyal V. Capital structure decisions // Working Paper, 2003.

19. Gervais S., Heaton J., Odean T. Overconfidence, investment policy, and executive stock options // Rodney L. White Center for Financial Research Working Paper, № 15-02, 2002.

20. Graham J., Harvey C. The theory and practice of corporate finance: evidence from the field // Journal of Financial Economics, 60, 2001, pp. 187-243.

21. Hackbarth D. Managerial Traits and Capital Structure Decisions // Working paper, 2004.

22. Heaton III J. Managerial optimism and corporate finance // Financial Management, v. 31, n. 2, 2002, pp. $33-45$.

23. Hovakimian A., Opler T., Titman S. The debt-equity choice // Journal of Financial and Quantitative Analysis, 36, 1, 2001, pp. 1-24.

24. Ikenberry D., Lakonishok J., Vermaelen T. Market underreaction to open market share repurchases // Journal of Financial Economics 39, 1995, pp. 181-208.

25. Jenter D. Market Timing and Managerial Portfolio Decisions // Journal of Finance, 60, 4, 2005, pp. 1903-1949.

26. Jung K., Kim Y., Stulz R. Timing, investment opportunities, managerial discretion, and the security issue decision // Journal of Financial Economics 42, 1996, pp. 159-185.

27. Kahneman D., Tversky A. Judgment Under Uncertainty: Heuristics and Biases // Science 185,1974, pp. $1124-31$.

28. Kahneman D., Tversky A. Prospect Theory: An Analysis of Decision Under Risk // Econometrica 47, 1979, pp. 263-91.

29. Kayhan A., Titman S. Firms' histories and their capital structures // Journal of Financial Economics 83 (1), 2007, pp. 1-32.

30. Kester C. Capital and ownership structure: a comparison of United States and Japanese manufacturing corporations // Financial Management 15, 1986, pp. 97-113.

31. Korajczyk R., Lucas D., McDonald R. The effect of information releases on the pricing and timing of equity issues // Review of Financial Studies 4, 1991, pp. 685-708.

32. Landier A., Thesmar D. Financial contracting with optimistic entrepreneurs // Working Paper, 2004.

33. Lasfer M.A. Agency Costs, Taxes and Debt: the UK Evidence // European Financial Management, Vol. 1, № 3, 1995, pp. 265-85.

34. Loughran T., Ritter J. The New Issues Puzzle // Journal of Finance, Vol. 50, № 1, 1995, pp. $23-51$.

35. Loughran T., Ritter J. The Operating Performance of Firms Conducting Seasoned Equity Offerings // Journal of Finance, 52, 1997, pp. 1823-1850.

36. Loughran T., Ritter J., Rydqvist K. Initial public offerings: International insights // Pacific-Basin Finance Journal, 2, 1994, pp. 165-199. 2002.

37. Malmendier U., Tate G. CEO overconfidence and corporate investment // Working Paper,

38. Marsh P. The choice between equity and debt: An empirical study // Journal of Finance, 37, 1982, pp. 121-144.

39. Mikkelson W., Partch M. Valuation effects of security offerings and issuance process // Journal of Financial Economics, 15, 1986, pp. 31-60.

40. Myers S. Determinants of Corporate Borrowing // Journal of Financial Economics, Vol. 5, № 2, 1977, pp. 147-175.

41. Myers S. Financing of corporations // In Constantinides, G., M. Harris, and R. Stulz (eds.) Handbook of the Economics of Finance, forthcoming, 2002.

42. Myers S., Majluf N. Corporate financing and investment decisions when firms have information that investors do not have // Journal of Financial Economics, 13, 1984, pp. 187-221. 
43. Ozkan A. Determinants of Capital Structure and Adjustment to Long Run Target: Evidence from UK Company Panel Data // Journal of Business Finance \& Accounting, Vol. 28, Nos. 1/2, 2001, pp. 175-198.

44. Pagano M., Panetta F., Zingales L. Why do companies go public? An empirical analysis // Journal of Finance, 50, 1998, pp. 1421-1460.

45. Rajan R., Servaes H. Analyst following of initial public offerings // Journal of Finance, 52, 1977, pp. 507-529.

46. Rajan R., Zingales L. What do we know about capital structure? Some evidence from international data // Journal of Finance, 50, 1995, pp. 1421-1460.

47. Shleifer A., Vishny R. Stock market driven acquisitions // Journal of Financial Economics, 70, 2003, pp. 295-311.

48. Teoh S., Welch I., Wong T. Earnings management and the long-term market performance of initial public offerings // Journal of Finance, 53, 1998, pp. 1935-1974.

49. Thomson S. The Role of Leasing in UK Corporate Financing Decisions, Accounting Treatment and Market Impact // PhD Thesis, University of Stirling, 2003.

50. Titman S., Wessels R. The determinants of capital structure choice // Journal of Finance, 43, 1988, pp. $1-19$.

51. Tversky A., Kahneman D. The Framing of Decisions and the Psychology of Choice // Science, 211, 1981, pp. 453-458.

52. Tversky A., Kahneman D. Advances in Prospect Theory: Cumulative Representation of Uncertainty // Journal of Risk and Uncertainty, 5, 1992, pp. 297-323.

53. Welch I. Capital structure and stock returns // Journal of Political Economy, 112, 2004, pp. 106-131. 